\title{
THE ENVIRONMENTAL EFFECTS OF INTRA-INDUSTRY TRADE IN THE SAARC REGION
}

\author{
Bilal Tariq \\ Universiti Malaysia Sarawak \\ Rossazana Ab. Rahim* \\ Universiti Malaysia Sarawak
}

\begin{abstract}
In the setting of globalization, the rising importance of international financial institutions and international relations as well as the emergence of environmental issues has inspired a new sense of political and economic interaction. Owing to these interactions, mode of trade has changed and it has resulted in the world trade reforms. Therefore, trade of differentiating goods is being appreciated and encouraged in developing economies. In the context of South Asian Association for Regional Cooperation (SAARC), the intra-industry trade is increasingly replacing inter-industry trade. The environmental effects of the aftermath of expansion in intra-industry trade i.e. scale effect, selection effect and technique effects in the SAARC region are to be assessed in this study. The overall results of this study indicate that if intraindustry trade is expanded, it yields positive impacts on the environment. At the one hand, the disintegration of trade induced environmental effects, implies that the scale effect is hazardous for the environment. On the other hand, the trade induced selection and technique effects are beneficial for the environment in the case of SAARC region.
\end{abstract}

Keywords: Intra-Industry Trade; Environmental Effect; SAARC.

\section{INTRODUCTION}

The environment is becoming an important issue in international trade, while trade liberalization is creating issues that are concerned with both trade and the environment. The pertinent questions are whether the resulting trade expansion pollutes the environment more or less than before? Does an emphasis on economies-of-scale in trade liberalization policies have triggered countries to evaluate their pollution emission? Trade expansion may have direct as well as indirect trade-induced environmental effects. The relationship between trade and environmental quality is ambiguous due to the structure of developing economies; sometime it is beneficial in the short run but harmful in the long run or vice versa (Cosbey, 2008). The debates on the international trade and environmental sustainability have generated more heat than light; trade liberalization has affected both trade and environment.

2 Corresponding author: Faculty of Economics and Business, Universiti Malaysia Sarawak, 94300 Kota Samarahan, Sarawak. Malaysia.E-mail: rossazana@gmail.com

1 Demand for pollution is from producers for producing goods while supply of pollution is from 
Economies with large polluting industries are blamed to be the major culprit of the environmental degradation, such as climate change. In the industrial sector, having features of increasing returns to scale with trade liberalization, total number of firms in the industry shrinks although each one of the remaining firms produces more than before. Trade expands the consumption basket and enables the consumers to use both local and imported varieties of goods. At the same time, when income level of a country increases due to the trade openness; the country implements stricter environmental approach, which causes amplified pollution abatement activity and lesser emission intensity (Fung and Maechler, 2007).

The South Asian Association for Regional Cooperation (SAARC) countries are actively participating in the world trade, both inter-trade and intra-industry trade. On this note, the volume of intra-industry trade is increasing in the SAARC region. Hence, the question is whether the increase in the intra-industry trade contributes to the environmental externalities in the region? Accordingly, this study investigates the trade and environment relationship by utilizing the new trade theory. The new trade theory refers to the imperfect competition, increasing returns to scale, choice of variety and specialization in a limited range of production of differentiated goods. Employing the new trade theory, this study examines the trade induced environmental effect which is classified further into the scale effect, selection effect and technique effect. Firstly, the scale effect refers to the variation in environmental quality due to change in scale of production while the selection effect refers to the change in environmental quality due to the change in number of firms; and finally, the technique effect is the impact of income on the quality of environment (Aralas, 2010). It is noteworthy that the selection effect is the main factor that differentiates the effect of inter-industry trade from the effect of intraindustry trade on the environment. The other effect of inter-industry trade is the composition effect which refers to a tradeoff between capital labor ratio and this effect provides the base of pollution haven hypothesis and race to bottom approach in the Hecksher-Ohlin framework (Taylor et al., 2001).

Existing studies generally ignored the selection effect due to the frequent use of overall trade induced environmental composition effect in the trade and environment literature. Trade induced environmental composition effect emphasizes on environmental effect of trade due to change in factor intensity. However, this study departs from the existing practice by focusing on the trade induced environmental selection effect instead of the composition effect. The environmental selection effect is the change in emission level due to the change in the selection of differentiated products, while trade induced environmental selection effect is the change in emission level due to change in the selection of differentiated products as a result of trade liberalization. In the absence of data on differentiated products, empirical studies such as Krugman (1979) and Feenstra (2003) suggest that the number of firms can be used as a proxy for differentiated products; thus, this study uses a number of listed firms to represent product differentiation. In other words, the environmental selection effect is a change in the level of emission due to the change in the selection of differentiated products (case of monopolistic competition) while the trade induced environmental selection effect is a change in the level of emission due to the trade of differentiated products. Lastly, the environmental technique effect refers to the relationship between income and emissions while trade induced environmental technique effect shows the relationship between income and emissions due to the trade liberalization. 
The mounting pace of trade in differentiated products shows that intra-industry trade is becoming a significant aspect of global trade. Intra-industry trade is explained by differentiated goods while inter-industry trade is explained by comparative advantages. Intra-industry trade is to import and export the same types of goods and services that fall in the same industry; while inter-industry trade refers to the exchange of goods that belong to different industries such as agricultural products against the computer (Bernatonyte and Normantiene, 2009). The production of differentiated goods is not free from environmental effects. They certainly degrade the environment, however questions arise, what is the nature of these effects? How does the trade affect the trading nations? And whose liability is to mitigate the environmental damages of trade? These questions are frequently asked in trade and environment literature, but recent developments in new trade theory open the new era for trade and environment research. New trade theory is becoming important over the time; hence, this study is an attempt to find out the impact of trade on the environment among the SAARC countries by applying the new trade theory.

Apart from that, there is a gap in the literature on trade and environment under the new trade theory. Aralas (2010) investigates the trade and environment relationship in Organization for Economic Co-operation and Development (OECD) countries by utilizing the new trade theory. To the best of the knowledge, there is no existing study is conducted in the context of SAARC region. Studies such as Fung and Maechler (2007) and Shahbaz et al. (2012) investigate the importance of conventional trade in the SAARC, but both mentioned studies do not incorporate the nexus between the intra-industry trade and the environment. In addition, Azhar et al. (2007) point out the long run implication of overall trade liberalization on the air pollution in SAARC region. Distinguishing itself from previous studies, this study attempts to fill the gap in the literature on intra-industry trade and environment, under the new trade theory in the SAARC region. Specifically, this study explores the trade-induced environmental effects, i.e., selection effect, scale effect and technique effect due to the intra-industry trade. The rest of the study is divided into four sections. Next section provides an overview on the SAARC countries follows by the section on the review of past studies. Subsequently, the methodology and the empirical results sections are presented and the final section offers conclusion of this paper.

\section{BACKGROUND OF THE SAARC REGION}

This section provides an overview on the overall economic structure, trade flows and patterns and air pollution in the SAARC region, namely; Afghanistan, Bangladesh, Bhutan, India, Maldives, Nepal, Pakistan and Sri Lanka. These countries differ greatly in land area, gross domestic product (GDP), population, trade patterns and environmental zones. Apart from sharing the common borders with each other, the SAARC countries also own similar level of human resources and economic development. For instance, India the largest country in this region in terms of land area has the highest population, the greatest share of GDP and gross net product (GNP) among other SAARC countries (Akram, 2012). Consequently, it explains why India has the greatest share of environmental degradation among SAARC countries (Behera et al. 2011). Interestingly, Pakistan and Bangladesh which share almost similar characteristics in terms of GDP, GNP and population structure; their combined share of trade in the SAARC region is considered close to India (Akram, 2012). Nevertheless, the contamination levels of air pollution of Pakistan and Bangladesh are more manageable relatively to India (Qureshi, 
2006). Sri Lanka, the smallest country in this region with the least share of total GDP, GNP, population and the land area of SAARC has the lowest trade share among other counterparts, but Sri Lanka has its own importance in the region (Akram, 2012). Table 1 below shows the commodity trade volumes of SAARC economies.

Table 1: Commodity Trade Statistics of SAARC Countries (Million USD 2011)

\begin{tabular}{lccc}
\hline \multicolumn{1}{c}{ Country } & Trade in Goods & $\begin{array}{c}\text { Inter-industry } \\
\text { Trade }\end{array}$ & $\begin{array}{c}\text { Intra-industry } \\
\text { Trade }\end{array}$ \\
\hline Afghanistan & - & - & - \\
Bangladesh & 8482.4 & 7858.6 & 623.7 \\
Bhutan & - & - & - \\
India & 131272.8 & 52246.6 & 79026.2 \\
Maldives & 276.6 & - & - \\
Nepal & 580.1 & - & - \\
Pakistan & 15904.8 & 11610.5 & 4294.3 \\
Sri Lanka & 3970.7 & 3101.1 & 869.6 \\
\hline
\end{tabular}

Source: United Nations Commodity Trade Statistics Database (2011).

Note: (-) means not available.

The SAARC region has huge capacity to establish itself as an effective trading bloc in the world; its population alone contributes 23 percent of the world population. By engaging in the intra-industry trade on the basis of product differentiation and economies of scale, these countries can enjoy the benefits from the intra-industry trade (Akram, 2012). Development of international institutions, rising nationalism and regional associations are the new senses of political and economic interaction (Tussie, 1998). Over the time, intra-industry trade volume is increasing and it is taking the place of inter-industry trade (Fung and Maechler, 2007).

However, there is a price they have to pay. Air pollution is becoming a common problem in the SAARC region. As an example, industrial hubs in Pakistan like Lahore, Karachi, Peshawar, Rawalpindi, Hyderabad, Faisalabad, Gujarat, Sialkot, and Gujranwala are creating serious environmental problems; the atmospheric levels of carbon mono oxide, sulfur-dioxide and nitrous oxides are higher than safe limits. Some industries are taking measures to control air pollution, however, technologies for controlling air contamination has not yet been adopted (Parekh et al. 2001). In Sri Lanka, the urban areas are badly affected by air pollution; about eighty percent industrial units in Sri Lanka are located in Colombo, Kalutara and Gampaha regions. Chemical, food and textile sectors contribute 40 percent of the air pollution (Wittman and Caron, 2009). In the case of Bangladesh, the air quality level in Dhaka is very poor due to the dust and vehicle emissions. Industrial discharges are noticeable in some highly populated and dense industrialized zones such Dhaka, Chittagong and Khulna. Nevertheless, the air quality problem is not very serious, partly because of prevailing natural environmental conditions which easily scatter the air emissions due to a flat topography and relatively high wind speeds most of the year (Qureshi, 2006). 
These countries have taken several measures; for instance, India is investing in air pollution control programs and awareness about the possible damages of air pollution is widely spread. As a result, manufacturing firms are required to attain prior agreement from environmental authorities before starting new operations and strict environmental standards have been set up for a number of highly polluting industries (Behera et al. 2011). In this vein, this study attempts to tackle the issue of trade and environment in major SAARC countries under the new trade theory.

\section{LITERATURE REVIEW}

A bulk of studies examines the historic trend of trade liberalization and emission levels; however, a little heed has been paid to link intra-industry trade with the environment. Intraindustry trade study was pioneered by Verdoorn (1960) and this concept has revolutionized the international trade theory and policy. Next, Grubel and Lloyd (1975) develop a popular index of intra-industry trade. Helpman and Krugman (1989) make various attempts to model intra-industry trade. Aralas (2010) extends the Krugman (1979) model of intra-industry trade by incorporating environmental impacts into the model. Alam (2010) examines the impact of overall trade liberalization, industrialization and human development on environmental degradation in Pakistan. The study also finds parallel effects of trade liberalization along with all other socioeconomic and demographic factors on economic growth. The results imply that industrial, agricultural activities and rapidly growing urbanization affect the environment badly, while trade liberalization and human development are environmental friendly.

Azhar et al. (2007) examine the long run coefficients of overall trade liberalization and scale effect, which are considerably associated with air and water contamination. Thus, scale effect of trade intensity is hazardous for the environment and the scale of production is positively related to pollution. On the contrary, the composition and the technique effects inversely associated with pollution, hence trade induced environmental composition and the technique effects are beneficial to the environment. The findings advocate that to attain the gains of trade liberalization, a sustainable development and high quality growth path, Pakistan needs to reduce the environmental costs related to the industrial development. Aralas (2010) critically reviews the trade and environment literature and proposes three issues: firstly, tradeenvironment relationship is mostly based on traditional trade theories; secondly, relationship between environment and new trade theory focuses on environmental regulations; and thirdly, there is no proper model that reveals the consequences of intra-industry trade for environmental performance in the closed and open economy.

Taylor et al. (2001) report that air pollution is directly associated with openness of trade and scale effect. The composition and technique effect are negatively related to pollution. This study utilizes inter-industry trade approach for measuring the trade-induced environmental effects. For regional investigation of intra-industry trade, Aralas`s (2010) model is favorable which is developed for OECD countries. Beghin et al. (2002) model examines the trade integration, environmental degradation, and public health in Chile. By using a CGE model, the study proves that without trade liberalization Chile has cheaper and dirtier energy sources which hamper the environment. However, if the trade liberalizes with appropriate environmental standards, there would be significant welfare gains for Chile. 
The above review of literature suggests that a large body of studies separately deals with the issue of international trade and environmental externalities. Only a few studies are available that bridge the issues of both disciplines to assess their causes and effects. Besides, only a few studies provide the linkage between intra-industry trade and environment by using the framework developed by the new trade theory. To the best of this study knowledge, there is no study available for the SAARC region that examines the relationship between intraindustry trade and environment. This study is therefore an attempt to fill this gap by employing econometric methods for the purpose of estimating the intra-industry trade and environmental relationship in SAARC region.

\section{METHODOLOGY}

The Aralas (2010) model which is based on the new trade theory (Krugman, 1979) is adopted in this paper. The Aralas model postulates the market structure is monopolistically competitive and firms produce differentiated goods; while pollution is a joint product. Firms have the same technology and produce goods with a large number of product varieties. Production technology is increasing returns to scale and producers are identical except in the design of their product; nevertheless, they are able to differentiate their products without incurring additional cost. Finally, countries are identical in size, technology and preference and there is zero transportation cost.

\subsection{Model Specifications}

\section{(a) Consumption}

There are $N$ numbers of consumers having similar preferences in the economy. Consumers do not derive utility from leisure. Each consumer receives positive utility from consuming $i^{\text {th }}$ good, but obtains negative utility from pollution. Social damage from pollution comes from disutility imposed on consumers. A consumer can maximize his utility within limited budget, in this framework total income is equal to consumer's wage, in this case consumer utility maximization can be expressed as follows.

$\max \mathrm{U}_{x_{i}}=\sum_{\mathrm{i}=1}^{\mathrm{n}} \mathrm{v}\left(\mathrm{x}_{\mathrm{i}}\right)-\sum_{\mathrm{i}=1}^{\mathrm{n}} z_{i}$

subject to: $\mathrm{y}=\mathrm{w}$

where:

$\mathrm{y}=\sum_{\mathrm{i}=1}^{\mathrm{n}} \mathrm{p}_{\mathrm{i}} \mathrm{x}_{\mathrm{i}}$ (the consumer can maximize his utility within limited budget)

$\mathrm{p}_{\mathrm{i}}=$ Price of the $i^{\text {th }}$ good

$u=$ Utility from consumption of goods

$n=$ Total number of varieties

$y=$ Total income

$i=$ Any particular variety

$x=$ Good providing utility

$w=$ Wage

$z_{i}=$ Disutility from pollution 


\section{(b) Production}

The model assumes the locally emitted pollutants and the trans-boundary pollutants are not considered. There is increasing returns to scale with initial positive fixed cost, constant marginal cost due to which average cost decreases in firms. A part of the output is allocated for abatement, $\mathbf{q}_{\mathbf{i}} \boldsymbol{\theta}$, remaining part $(\mathbf{1}-\boldsymbol{\theta}) \mathbf{q}_{\mathbf{i}}$ is sold in the market for consumption purpose. This relationship can be expressed by the following form:

$(1-\theta) q i=L x_{i} ; 0 \leq \theta<1$

where:

$\theta=$ Abatement of pollution

$q_{i}=$ Output

$L=$ Total number of labor employed in production

In Equation (2) $\mathrm{Lx}_{\mathrm{i}}$ is total demand (local produced goods + imports) and $(1-\theta) \mathrm{q}_{\mathrm{i}}$ is the total supply (local supplied goods + exports) after adjusting for the abatement activity. A tight environmental policy obliges the firms to cut down the emissions and start greater abatement activity. The domino effect of the policy is a decrease in the emission intensity per unit of output.

$e=\left(\frac{w \beta}{\tau(\varnothing-1)}\right)$

where:

$e \geq 0, \beta \geq 0, \tau \geq 0$

$e=$ Emissions per unit of output

$w=$ Wage

$\beta=$ Labor coefficient

$\tau=$ Emission tax rate

$\emptyset=$ Change in emission intensity due to change in part of output allocated for consumption

Emission per unit of output or the emission intensity is denoted by $e_{i}$. $e_{i}$ is equal to $\frac{z_{i}}{q_{i}}$, the relationship between emissions and emission per unit of output is given as:

$\mathrm{z}_{\mathrm{i}}=\mathrm{e}_{\mathrm{i}} \mathrm{q}_{\mathrm{i}}$

$\tau=-\left[\left(\frac{1}{\psi}\right) \varphi \rho^{-1}\left(\frac{w \beta}{(\emptyset-1)}\right) q\right]^{\frac{1}{(1+\rho)}}$

where:

$\psi=\left(n p^{\frac{\rho}{(\rho-1)}}+n^{*} p^{* \frac{\rho}{(\rho-1)}}\right)^{1-\rho}$ 
Emission tax is given by Equation (5) and it can also be expressed in the functional form as:

$$
\tau=\tau(\psi, w, \beta, \rho)
$$

where:

$\beta=$ Productivity of labor parameter.

$\rho=$ The preference parameter.

$\varphi=$ Marginal disutility of pollution.

$w=$ Wage.

$n=$ Number of domestic firms.

$\psi=$ Domestic and foreign product varieties.

$p=$ Domestic price.

$n^{*}=$ Number of foreign firms.

$p^{*}=$ Foreign price level.

Negative sign in Equation (5) on the right hand side is due to the marginal disutility of pollution $(\varphi)$. Based on Equation (2), Equation (4) can be rewritten as:

$z_{i}=e_{i} q_{i} \Rightarrow \sum_{\mathrm{i}=1}^{\mathrm{n}} \mathrm{e}_{\mathrm{i}} q_{i}=\sum_{\mathrm{i}=1}^{\mathrm{n}} \mathrm{e}_{\mathrm{i}}\left(\frac{\mathrm{Lx}_{\mathrm{i}}}{\left(1-\theta_{\mathrm{i}}\right)}\right)$

Total labor, $L$, in the closed economy, is predetermined and balance across firms, this implies that:

$\sum_{i=1}^{n} z_{i}=\frac{L \sum_{i=1}^{n} e_{i} x_{i}}{\left(1-\theta_{i}\right)} \Rightarrow n z=L . n . e x /(1-\theta)$

Letting $n z=Z$ is the total pollution due to the production and Equation (6a) can be explained by rewriting in differential form (hats indicate the percentage change yields):

$\hat{Z}=\hat{n}+\hat{e}+\hat{q}$

Equation (7a) can be written in more detailed form:

$\hat{Z}=\hat{n}+\hat{L}+\hat{x}+\hat{e}-(1-\hat{\theta})$

Equation (7b) decomposes the pollution into:

Selection effect $=(\widehat{n})$

Scale effect $\quad=(\hat{L}+\hat{x}-(1-\hat{\theta}))$

Technique effect $=(\hat{e})$ 
where, $\widehat{Z}$ is the percentage change in total emission, $\widehat{\mathrm{n}}$ is percentage change in number of firms due to openness of trade or trade liberalization, $\widehat{e}$ is the percentage change in number of emission per unit output due to openness of trade and $\widehat{\mathrm{q}}$ is percentage change in output after change in trade intensity. Equations (7a) and (7b) basically show the impact of intra-industry trade on environment that is a sum of scale, technique and selection effects.

Equation (7b) shows the demand for pollution while Equation (5) is the supply of pollution from a regulatory authority. ${ }^{1}$ After decomposing Equation (5) into its basic determinants and by joining demand and supply for pollution, a reduced form equation is derived:

$$
\hat{Z}=\Lambda_{1} \hat{n}+\Lambda_{2} \hat{S}+\Lambda_{3} \widehat{w}+\Lambda_{4} \widehat{n}^{*}+\Lambda_{5} \hat{p}^{*}+\Lambda_{6} \hat{L}+\Lambda_{7} \hat{\rho}+\Lambda_{8} \hat{\beta}+\Lambda_{9} \widehat{\emptyset}+\Lambda_{10} \widehat{\varphi}
$$

Equation (8) recounts the emission level due to the economic variables. The level of emissions is affected by the total number of domestic firms ( $\mathbf{n}$ ), the output produced for the purpose of consumption ( $\mathbf{s})$, Wage ( $\mathbf{w})$, imported product varieties $\left(\mathbf{n}^{*}\right)$, the world price level $\left(\mathrm{p}^{*}\right)$, factor of production in the economy ( $\mathbf{L}$ ), the preference parameter $(\boldsymbol{\rho})$, the productivity of labor parameter ( $\boldsymbol{\beta}$ ), the elasticity of emission with respect to the fraction output allocated towards consumption $(\varnothing)$ and the marginal disutility of pollution $(\boldsymbol{\varphi})$.

\section{(c) Environmental Effects in Closed Economy}

Since measures and data for SAARC countries, particularly on $\beta, \rho, \varnothing$ and $\varphi$ are not available; therefore they are studied as unobserved country parameters in the model. Equation (7a) which is decomposed into environmental scale, selection and technique effect can be expressed by using a linear form of emissions in metric tons per square kilometer with respect to time $(t)$ and country $(k)$ in the following equation:

$Z_{k t}^{c}=\alpha_{0}+\alpha_{1} F I R M_{k t}+\alpha_{2} S C A L E_{k t}+\alpha_{3} I N C_{k t}+u_{k t}$

$\mathrm{Z}_{\mathrm{kt}}^{\mathrm{c}}$ is emission of $\mathrm{CO}_{2}$ per square kilometer. The basic reason of using $\left(\frac{\mathrm{CO}_{2}}{\mathrm{~km}^{2}}\right)_{\mathrm{kt}}$ is standardization of emission according to the size of the country. The comparison of the emission level without standardization is irrational. Because, India is a very big country and Sri Lanka is very small as compared to other countries. Without standardization of emissions, results will be biased, which may be unreliable. Taylor et al. (2001) use this technique to analyze trade and environment relationship for OECD countries by using different pollutants.

$F I R M_{k t}$ is used to show the environmental selection effect. This effect is due to a change in the number of firms in the economy on the basis of selection of product variety. FIRM includes all kinds of companies, which are engaged in production of goods. FIRM is basically

1 Demand for pollution is from producers for producing goods while supply of pollution is from regulatory authority, because the government allows producers to produce goods which emit pollution (Taylor et al., 2001). 
density of firms in per squared kilometer of country $\mathrm{k}$ at time t. The theory suggests that in general, the greater the firm's density is, the greater is the level of pollution. In the empirical model FIRM $M_{k t}$ is the country-specific number of listed companies per squared kilometer. Total number of firms in large economy, such as in India is very high and the number of firms in a small economy such as Sri Lanka is very small. Thus, without standardization the results may be biased. Following Aralas (2010), this study used $\left(\frac{\text { No.ofListed companies }}{\mathrm{km}^{2}}\right)_{k t}$ for standardization of $(F I R M)_{k t}$ variable.

$S C A L E_{k t}$ is used to show the environmental scale effect. Scale of production is the production of all goods and services within the boundary of a country. In the empirical model scale of production is measured by the gross domestic product (GDP). It is hypothesized that the greater is the scale of production greater is the level $\mathrm{CO}_{2}$ emissions. Following Taylor et al. (2001), the scale of production $(S C A L E)_{k t}$, which is country-specific and it is defined as $\left(\frac{G D P}{k m^{2}}\right)_{k t} . I N C_{k t}$ shows environmental technique effect. $I N C_{k t}$ is basically national income of a country. In the trade environment and environmental Kuznets curve (EKC) literature this variable is frequently used by environmental economist. In the empirical model the income of a country $k$ is represented by $(I N C)_{k t}$ which is income per capita $\left(\frac{G N P}{L}\right)_{k t}$. The purpose of using per capita of a variable is standardization. Taylor et al. (2001) and Aralas (2010) use $\left(\frac{G N P}{L}\right)_{k t}$ in their research. India is a large country in the SAARC region and its gross national income (GNI) is not comparable with other countries like Pakistan, Bangladesh and Sri Lanka but GNI per capita is comparable.

\section{(d) Environmental Effects in the Open Economy}

Equation (9a) does not express the effect of trade liberalization, so a trade variable is included in Equation (9a). and it can be rewritten as:

$Z_{k t}^{c}=\alpha_{0}+\alpha_{1}$ FIRM $_{k t}+\alpha_{2} S C A L E_{k t}+\alpha_{3} I N C_{k t}+\alpha_{4} T R_{k t}+u_{k t}$

$T R_{k t}$ is used to examine the effect of overall trade on the level of emissions. $(T R)_{k t}$ is defined as the openness of trade in term of trade intensity and calculated as the import plus export ratio to GDP $\left(\frac{(X+M)}{G D P}\right)_{k t} \cdot k$ is used to show the $\mathrm{k}^{\text {th }}$ country and $t$ is used for a specific time period.

Trade intensity is thus the share of total trade in the GDP. The greater the share of trade in the GDP, the greater the trade intensity of a country and as a result, the economy will be more open to the foreign competition. Previous studies such as Fung and Maechler (2007), Aralas (2010), Shaista and Rehman (2011) and Taylor et al. (2001) utilize this variable to assess the impact of trade on the environment. 


\subsection{Model Estimations}

\section{(a) Linear Model of Trade-induced Environmental Effects}

Equation (9b) only shows the effect of selection of product variety, scale of production, income and trade on the environment. However, it does not represent the trade-induced environmental effects; namely, trade-induced environmental selection effect, trade-induced environmental scale effect and trade-induced environmental technique effect. To derive trade-related environmental effects, an interaction term $T R_{k t}$ can be introduced along with the variables representing the scale of production, income per capita, and number of firms to represent the trade-induced environmental scale, technique and selection effects. Following is the linear model that can be used to examine the trade-induced environmental effects which is called as Model A:

$Z_{k t}^{c}=\alpha_{0}+\alpha_{1}$ FIRM $_{k t}+\alpha_{2}$ SCALE $_{k t}+\alpha_{3} I N C_{k t}+\alpha_{4} T R_{k t}+\alpha_{5} S L T R_{k t}+\alpha_{6} S C T R_{k t}+$ $\alpha_{7}$ TECTR $_{k t}+u_{k t}$

(Model A)

where, $S L T R_{k t}$ variable shows the change that trade brings about in number of firms.

Trade creates a fall in the number of firms due to economies of scale to the firms. This is because economies of scale make it valuable for a country to specialize in the production of only a limited range of products. The effect of a change in the number of firms on the level of emissions as a result of the change in trade intensity is called trade-induced environmental selection effect. In the empirical specification, the domestic companies per squared kilometer along with the openness of trade is trade-induced environmental selection effect $(S L T R)_{k t}$, this effect differentiates the intra-industry trade from inter-industry trade. In other words, it is used to show the intra-industry-trade-induced environmental selection effect (Aralas, 2010).

$S C T R_{k t}$ variable shows that change in the trade intensity brings a change in scale of production. The effect of the change in scale of production at the level of emissions due to a change in trade intensity is called 'trade-induced environmental scale effect'. In the empirical specification $S C T R_{k t}$ is the $k_{t h}$ country`s gross domestic product per squared kilometer which is interacted with trade intensity at time $t$ (see Aralas, 2010; and Taylor et al., 2001). Income per capita is used to determine the environmental technique effect. To find the trade-induced environmental technique effect, the income per capita is interacted with trade intensity $(T E C T R)_{k t}$. Taylor et al. (2001) and Aralas (2010) both employ the trade-induced environmental technique effect in their work on the trade and environment. Trade-induced environmental technique effect shows the effect of change in the income level on the level of emissions as a result of changes in the trade intensity.

\section{(b) Quadratic Model of Trade-induced Environmental Effects}

The use of per capita national income and trade intensity and their non-linear effects are consistent with some studies of the $\mathrm{EKC}$, pollution haven hypothesis, race to the bottom and resource curse hypothesis. Taylor et al. (2001) and Aralas (2010) suggest an alternative 
specification, by including squared terms to the general linear representation in their models; therefore, this study represents a non-linear representation in Model B. The EKC also advocates that trade and environmental relationship is not linear. It may be quadratic or cubic. To resolve the above mentioned possibilities, following functional form is designed as Model B.

$$
\begin{gathered}
Z_{k t}^{c}=\alpha_{0}+\alpha_{1} \text { FIRM }_{k t}+\alpha_{2} S C A L E_{k t}+\alpha_{3} I N C_{k t}+\alpha_{4} I N C_{k t}^{2}+\alpha_{5} T R_{k t}+\alpha_{6} T R_{k t}^{2}+ \\
\alpha_{7} \operatorname{SLTR}_{k t}+\alpha_{8} S C T R_{k t}+\alpha_{9} T E C T R_{k t}+u_{k t}
\end{gathered}
$$

\section{(c) Measurements of Variables}

This study uses number of domestic companies listed in the stock market, to represent the $F I R M_{k t}$; it is represented by the number of listed domestic companies per square kilometer $\left(\frac{\text { No.ofListed companies }}{\mathrm{km}^{2}}\right)_{k t}$. The scale effect can be calculated by dividing the gross domestic product per square kilometer $\left(\frac{G D P}{k m^{2}}\right)_{k t}$. Per capita national income can be reflected by gross national product per capita $\left(\frac{G N P}{L}\right)_{k t}$ earned. The total trade of the country is sum of import and export. Openness of trade is total trade to GDP ratio $\left(\frac{(X+M)}{G D P}\right)_{k t}$. The Trade-induced environmental selection effect is represented by $\left(\frac{\text { No.ofListed companies }}{\mathrm{km}^{2}}\right)_{k t}$ $*\left(\frac{(X+M)}{G D P}\right)_{k t}$ while the trade-induced environmental scale effect is represented by $\left(\frac{G D P}{k^{2}}\right)_{k t}$ $*\left(\frac{(X+M)}{G D P}\right)_{k t}$. Last but not least, the trade-induced environmental technique effect is represented by $\left(\frac{G N P}{L}\right)_{k t} *\left(\frac{(X+M)}{G D P}\right)_{k t}$.

\section{RESULTS AND DISCUSSION}

Data on GDP, GNP, import, export, population, $\mathrm{CO}_{2}$ emission and number of listed companies are taken from World Development Indicators. GDP, GNP, export and import data are used in dollar term with the base year 2000. The study period spans 23 years from 1988 to 2010 and cross sections of four countries, namely; India, Pakistan, Bangladesh and Sri Lanka.

\subsection{Panel Unit Root Tests}

Panel data consist of both time-varying and time-invariant regressors; there is a probability of having correlation between the error terms and the presence of the heteroscedasticity. The presence of a unit root in the panel data series at the level may have some econometric 
problems, thus, the unit root is removed. The first difference in these series is taken and then again testing the presence of the unit root. That is, non-stationary time series are I (1) process. Then these I (1) series are included in the analysis.

\subsection{The Hausman Test}

The Hausman test rejects the random effects model in favor of the fixed effects models in the case of Model A. It is concluded that the fixed effect (FE) estimates are efficient and consistent as compare to those of random effect (RE) estimates. In describing the Model B, Hausman test suggests that the FE model is a more appropriate model for estimation as compared to the RE model; thus the FE estimates are more efficient and consistent as compared to those of RE estimates. This finding denotes that the relationship of intra-industry trade with environmental degradation in SAARC region is affected by fixed events rather than the random events.

Table 2: Test Summary of Hausman Test

\begin{tabular}{lccc}
\hline \multicolumn{1}{c}{ Test Summary } & Chi-Sq. Statistic & Chi-Sq. d.f. & Prob. \\
\hline Model A & 60.546 & 7 & 0.0001 \\
Model B & 64.976 & 9 & 0.0001 \\
\hline
\end{tabular}

\subsection{Empirical Results}

Model A is a linear model for trade-induced environmental effects, in Model A dependent variable $Z_{k t}^{c}$ is pollution and $\mathrm{CO}_{2}$ emissions represent the pollution variable. Squared terms of $T R$ and $I N C$ are included in Model B as the relationship between $T R$ and INC is nonlinear. Openness of trade and per capita gross national income effects can also be explained in quadratic form bitterly. The EKC also verifies a nonlinear relationship of these variables. Therefore, square terms of trade openness and per capita gross national income are included. The sign of $(F I R M)_{k t}$ coefficient is negative in model A and B and it is statistically insignificant. However, in the case of production of differentiated goods; the process of fragmentation increases along with assembling procedure; while the level of emission decreases. When the number of firms is small, the smaller the activity of assembling and firms have to do all processing from beginning to end, which is the cause of greater level of emissions during the production (Hart and Ahuja, 1996), it explains the negative sign of $(F I R M)_{k t}$. This sign shows that when the number of firms per square kilometer decreases by one unit, the pollution increases by 0.169 units and vice versa in Model A. The negative sign of $(\text { FIRM })_{k t}$ coefficient in Model B shows that when the number of firms per square kilometer decreases by one unit, the pollution increases by 0.161 units and vice versa.

Second variable in Model A and B which is $S C A L E_{k t}$, the findings show that the variable is statically significant. The sign of $S C A L E_{k t}$ coefficient in Model A shows that when scale of production of an economy increases by one unit, the level of $\mathrm{CO}_{2}$ emissions will increase by 0.397 units (see Table 3). The sign of $S C A L E_{k t}$ coefficient in Model B shows that when scale 
of production increases by one unit, the level of $\mathrm{CO}_{2}$ emissions will increase by 0.622 units (Table 3). The increase in scale of production may be beneficial for the economy but it is harmful to the environment. Taylor et al. (2001) also justifies harmful outcomes of the scale effect for environmental quality, which is used in this study. Finding of Azhar et al. (2007) also point out that scale effect are considerably associated with air and water contamination. Thus, scale effect of trade intensity is hazardous for the environment and the scale of production is positively related to pollution.

Table 3: Estimation Results of the Linear Model of Environmental Effects

\begin{tabular}{lccc}
\hline & Variable & Model A & Model B \\
\hline & C & $-0.498(0.000)$ & $-1.180(0.000)$ \\
FIRM & $-0.169(0.101)$ & $-0.161(0.023)$ \\
SCALE & $0.397(0.000)$ & $0.622(0.000)$ \\
& INC & $0.802(0.000)$ & $2.381(0.000)$ \\
TR & $0.492(0.000)$ & $0.249(0.000)$ \\
& SLTR & $0.172(0.073)$ & $0.082(0.213)$ \\
& SCTR & $0.328(0.000)$ & $0.335(0.000)$ \\
& TECTR & $-0.497(0.000)$ & $-0.510(0.000)$ \\
R-squared & INC^2 & - & $-0.568(0.000)$ \\
Adjusted R-squared & - & $-0.109(0.000)$ \\
Log likelihood & & 0.937 & 0.952 \\
F-statistic & & 0.935 & 0.951 \\
Durbin-Watson stat & 119.06 & 144.03 \\
& & 617.25 & 868.07 \\
\hline
\end{tabular}

Note: Figures in parentheses represent the p-values.

The coefficient of $I N C_{k t}$ is positive in Model A and B. This coefficient shows, one unit change in $\mathrm{INC}_{\mathrm{kt}}$ variable brings 0.802 units change in the level of $\mathrm{CO}_{2}$ emissions in Model $\mathrm{A}$ and one unit change in $I N C_{k t}$ variable brings 2.381 units change in the level $\mathrm{CO}_{2}$ emissions in Model $\mathrm{B}$ in the same direction (see Table 3). Boopen and Vinesh (2011) also justify the positive relationship of income and $\mathrm{CO}_{2}$ emissions.

The sign of trade variable coefficient is positive in both models. The economic and environmental interpretation of positive sign shows that one unit change in trade intensity brings 0.492 units change in the level of emissions in model A and 0.249 units change in the level of emissions in the same direction in Model B (Table 3). The positive sign is due to the brown technology. SAARC is developing a region and SAARC countries adapt used and brown technology of developed countries. This sign may also be positive due to trade of dirty goods. Dean (2002) also claims that trade liberalization has negative impact on environmental quality. 
But the sign of trade-induced environmental selection effect $(S L T R)_{k t}$ is according to the expectations. One unit change in $(S L T R)_{k t}$ brings 0.172 units change in the level of emissions in Model A and one unit change in $S L T R_{k t}$ brings 0.082 units change in the level of $\mathrm{CO}_{2}$ emissions in Model B. Intra-industry trade-induced environmental selection effect shows that due to competition with the trade opening amount of firms decrease, this decrease in the number of firms has a positive impact on the environment (Table 3).

Aralas (2010) states that when trade opens total number of firms decrease in the region, to meet the demand of the region, the remaining firms in the industry have to increase their scale of production, this is cause of increase in the level of pollution. The coefficient of trade-induced environmental scale effect shows that one unit change in (SCTR) ${ }_{k t}$ brings 0.328 units change in the level of emissions in Model A and brings 0.335 units increase in the level of emissions in the same direction in Model B. In the analysis, trade-induced environmental scale effect shows that increase in scale of production as a result of the openness of trade is a source of increase in the level of emissions.

Sign of trade-induced environmental technique effect $(T E C T R)_{k t}$ is also according to the theory. This sign is negative and shows that increase in per capita national income due to trade enhancement improves the environmental quality. The coefficient of TECTR $\mathrm{kst}_{\mathrm{s}}$ shows that a one unit increases in $T E C T R_{k \mathrm{t}}$ brings 0.497 units reduction in the level of emissions in Model A and decreases the level of emissions 0.51 units in Model B (Table 3). Taylor et al. (2001) and Azhar et al. (2007) support the contention that trade-induced environmental technique effect is environment friendly.

The squared term of $I N C_{k t}$ shows that increase in income level is a source of decrease in the level of emissions and vice versa. The value of coefficient $\left(I N C_{k t}\right)^{2}$ is -0.568 this shows that one unit change in quadratic term of $I N C_{k t}$ brings 0.568 units reduction in the level of $\mathrm{CO}_{2}$. This negative sign also justifies the inverted U-shaped EKC states that higher the income level the better the environmental quality or the lesser polluted environment.

Trade intensity in square term shows a negative impact on the level of emission. The sign of the coefficient is according to the theoretical framework and the expectations. Negative sign shows that this variable is beneficial for the environment. This variable shows that one unit increases in square term of trade intensity brings -0.109 units change in the level of $\mathrm{CO}_{2}$ emissions (Table 3). Results of both squared term of per capita gross national income and trade intensity are according to theory. The negative sign of the squared term of trade liberalization or trade intensity very much supportive in trade and environmental quality analysis to justify that higher the trade intensity the better the environmental quality.

$\mathrm{R}^{2}$ and adjusted $\mathrm{R}^{2}$ are 0.937 and 0.935 in Model $A$ and 0.952 and 0.951 in Model B, respectively, show that the estimation is highly explained. The value of $\mathrm{R}^{2}$ is high because the time period is long and the cross sections are very short. Values of $\mathrm{R}^{2}$ and adjusted $\mathrm{R}^{2}$ show that Model $\mathrm{A}$ and $\mathrm{B}$ are a best fitted model. The $F$-stat is 617.25 in mode-A and 868.07 in Model B, which is quite robust. The F-statistic shows that variables of Model A and B are highly significant in the estimation. 


\section{CONCLUSION}

International trade deals with both homogenous and differentiated goods. Trade-induced environmental effects of an integrated open economy can be expressed by factors which are used for inter-industry as well as intra-industry trade. In this study, an investigation of panel data from SAARC countries provides the evidence of the following results. Strong empirical indication, from the analysis, supports the hypotheses postulated by the theory that emission levels of $\mathrm{CO}_{2}$ is increasing due to environmental technique effect, while decreasing due to trade-induced environmental technique effect. The coefficient of environmental scale effect in Model A is 0.397 which is greater than the coefficient of trade-induced environmental scale effect estimated in Model A (i.e., 0.328). It implies that trade is better for the environment. On the other hand the coefficient of environmental scale effect in Model B is 0.622 which is also greater than the coefficient of trade-induced environmental scale effect in Model A (i.e., 0.335). This coefficient also verifies that trade is beneficial for the environment. Increase in trade intensity/openness of trade is beneficial for the quality of the environment. Model B shows that the coefficient of trade-induced environmental selection effect is 0.082 which is relatively better than the coefficient of trade-induced environmental selection effect $(0.172)$ in Model A. The coefficient of overall trade is 0.249 in Model B, while the coefficient of trade in square term is -0.109 . This coefficient explains that the trade liberalization has a positive impact on environmental quality.

Trade-induced environmental technique effect is beneficial for the environment, while environmental technique effect is hazardous for environment in both Model A and B. In Model $\mathrm{B}$ environmental technique effect is initially hazardous for the environment due to increase in income, but as income intensity increases this environmental technique effect becomes a source environmental improvement. The results of the analysis are expected to resolve the some of the issues on trade and environment debate in the SAARC region, whether intraindustry trade is good or bad for the environmental quality?

In the light of the findings, policy of trade liberalization is suggested as a mean of stimulating economic growth in developing countries and simultaneously should have connected agenda with regards to environmental issues. Given the potential benefits of trade liberalization policies, it is very important to examine whether such policies are pro-environment or anti-environment. The links between trade and the environment are multiple, complex and important. Thus, the policy makers should be aware of the trade-off between economic growth and environmental sustainability. Environmental regulations can be based on a win-win situation for economists and environmentalists by involving all stakeholders of inter-industry and intra-industry trade in the region to improve the environmental quality. Following are some policy recommendations to solve the environmental problems.

Inter-industry trade is the source of $\mathrm{CO}_{2}$ emissions. Intra-industry trade is also a source of $\mathrm{CO}_{2}$ emissions but to a lesser degree. Trade-induced environmental selection effect can be controlled by creating a competitive environment in the SAARC region that can be ensured by focusing more on intra-industry trade. Furthermore, hazardous effects of intra-industry trade can be removed by investing more on the green technology and research and development. Scale of production is a major source of increase in $\mathrm{CO}_{2}$ emissions. Therefore, it is recommended that 
the scale of production should be achieved through the application of the technology, which is likely to be reducing the level of pollution. Initially the GNP per capita may be harmful to the environment, but with the passage of time, it creates beneficial impacts for the environment. Therefore, environmental quality should be improved by making concentrating efforts to increase the level of income on a sustained basis.

Trade brings greater income for the country that allows it to allocate more resources for education and environmental awareness, which in turn enables and motivates the people to demand better environmental standards. Besides, additional income earned from trade can be directly used for environmental improvements. Therefore, we strongly recommend that, our policymakers introduce policies that promote and expand trade in the SAARC region.

\section{ACKNOWLEDGEMENT}

Financial support from the Universiti Malaysia Sarawak (UNIMAS) and Fundamental Research Grant Scheme [FRGS/05(36)/844/2012(84)] are gratefully acknowledged. All remaining flaws are the responsibilities of the authors.

\section{REFERENCES}

Akram, A., \& Mahmood, Z. (2012). Determinants of intra-industry trade between Pakistan and selected SAARC Countries. The Pakistan Development Review, 51(1), 47-59.

Alam, S. (2010). Globalization, poverty and environmental degradation: Sustainable development in Pakistan. Journal of Sustainable Development, 3(3), 103-114.

Aralas, S. B. (2010). Essays in Trade and Environment: The Environmental Effects of Intraindustry Trade. Michigan State University, USA: Proquest, Umi Dissertation Publishing.

Azhar, U., Khalil, S., \& Ahmed, M. H. (2007). Environmental effects of trade liberalisation: a case study of Pakistan. The Pakistan Development Review, 46(4), 645-655.

Beghin, J. C., Bowland, B. J., Dessus, S., Roland-Holst, D., \& Van der Mensbrugghe, D. (2002). Trade integration, environmental degradation, and public health in Chile: assessing the linkages. Environment and Development Economics, 7(2), 241-267.

Behera, S. N., Sharma, M., Dikshit, O., \& Shukla, S. P. (2011). GIS-based emission inventory, dispersion modeling, and assessment for source contributions of particulate matter in an urban environment. Water, Air, and Soil Pollution, 218(1-4), 423-436.

Bernatonyte, D., \& Normantiene, A. (2009). Estimation of trade specialization: The case of the Baltic states. Inzinerine Ekonomika-Engineering Economics, 2(7), 25-36.

Boopen, S., \& Vinesh, S. (2011). On the relationship between CO 2 emissions and economic growth: the Mauritian experience. EDiA Paper No. 776.2011.

Cosbey, A. (2008). Border carbon adjustment. Canada: International Institute for Sustainable Development (IISD). 
Dean, J. M. (2002). Does trade liberalization harm the environment? A new test. Canadian Journal of Economics/Revue canadienne d'économique, 35(4), 819-842.

Feenstra, R. C. (2003). Advanced International Trade: Theory and Evidence. Princeton: Princeton University Press.

Fung, K. C., \& Maechler, A. M. (2007). Trade liberalization and the environment: The case of intra-industry trade. The Journal of International Trade \& Economic Development, 16(1), 53-69.

Grubel, H. G., \& Lloyd, P. J. (1975). Intra-industry trade: the theory and measurement of international trade in differentiated products. London: Macmillan.

Hart, S. L., \& Ahuja, G. (1996). Does it pay to be green? An empirical examination of the relationship between emission reduction and firm performance. Business Strategy and the Environment, 5(1), 30-37.

Helpman, E., \& Krugman, P. R. (1989). Trade Policy and Market Structure. Cambridge: MIT Press.

Krugman, P. R. (1979). Increasing returns, monopolistic competition, and international trade. Journal of international Economics, 9(4), 469-479.

Parekh, P. P., Khwaja, H. A., Khan, A. R., Naqvi, R. R., Malik, A., Shah, S.A. \& Hussain, G. (2001). Ambient air quality of two metropolitan cities of Pakistan and its health implications. Atmospheric Environment, 35(34), 5971-5978.

Qureshi, M. S. (2006). Trade Liberalization, Environment and Poverty: A Developing Country Perspective. UNU-WIDER Research Paper 45/2006.

Shahbaz, M., Leitao, N. C., \& Butt, M. S. (2012). Pakistan intra-industry Trade: A panel data approach. International Journal of Economics and Financial Issues, 2(2), 225-232.

Shaista, A., \& Rehman, S. (2011). Trade Liberalization, Environmental Degradation and Sustainable Development in Pakistan. European Journal of Social Sciences ,19(1), 84-96.

Taylor, M. S., Antweiler, W., \& Copeland, B. R. (2001). Is free trade good? For the environment. American Economic Review, 94(1), 877-908.

Tussie, D. (1998). Globalization and world trade: from multilateralism to regionalism. Oxford Development Studies, 26(1), 33-45.

UN (2011). Commodity Trade Statistics Database. New York, USA: United Nations.

Verdoorn, P. J. (1960). The Intra-Block Trade of Benelux. Economic Consequences of the Size of Nations. London: Macmillan.

Wittman, H. K., \& Caron, C. (2009). Carbon offsets and inequality: social costs and co-benefits in Guatemala and Sri Lanka. Society and Natural Resources, 22(8), 710-726. 